\title{
A critique: "Potassium requirements of pasture on Pumice soil" by Morton et al.
}

\author{
D.C. EDMEADES ${ }^{1}$ and R.M. McBRIDE ${ }^{1}$ \\ agKnowledge Ltd, PO Box 9147, Hamilton 3240 \\ doug.edmeades@agknowledge.co.nz
}

\begin{abstract}
Morton et al. (2014) presented the results from two rates of potassium $(\mathrm{K})$ pasture trials conducted on Pumice soils which commenced in spring 2009 and ran for 3 years. They reached a number of conclusions with respect to the management of potassium requirements on such soils, based on the soil Quick Test K (QTK) samples $(0-75 \mathrm{~mm})$ collected in spring and suggested that the results from these two sites were unique. While noting that soil samples were collected in the autumn, they did not include these data in their anaylsis and discussion of the results. This communication discusses the implications of this omission.
\end{abstract}

Keywords: potassium, pasture, pumice, soil tests

\section{Introduction}

In 2014 Morton et al. presented the results from two pasture trials on rates of potassium $(\mathrm{K})$ conducted on Pumice soils, one at Mamaku and the other at Whakamaru. Both commenced in spring 2009 and ran for 3 years.

Various measurements were made including: pasture production, clover content and production, and the potassium $(\mathrm{K})$ concentration in the clover. Soil samples were collected initially, before the treatments were applied, and then each year in autumn, to three soil depths: 0-75 $\mathrm{mm}, 75-150 \mathrm{~mm}$ and $150-300 \mathrm{~mm}$, and again in spring (0-75 mm only). Morton et al. (2014) concluded, based on the spring soil test results $(0$ $75 \mathrm{~mm}$ ) that:

1. “...95\% relative yield was achieved at [Quick Test K] QTK 3 from these sites....."

2. " ...these pumice soils do not require such a high soil QTK for near maximum pasture production compared with the average pumice soil"

3. "Even very high rates of 300-600 kg K/ha/yr failed to elevate the soil QTK into the target range for nearmaximum pasture production of 7-10"

They did note in their paper that: "Autumn soil QTK levels were always higher than the spring levels at both sites...", but nevertheless they did not include the autumn soil test results in their analysis or discussion of the data. This communication explores the consequences of this omission.

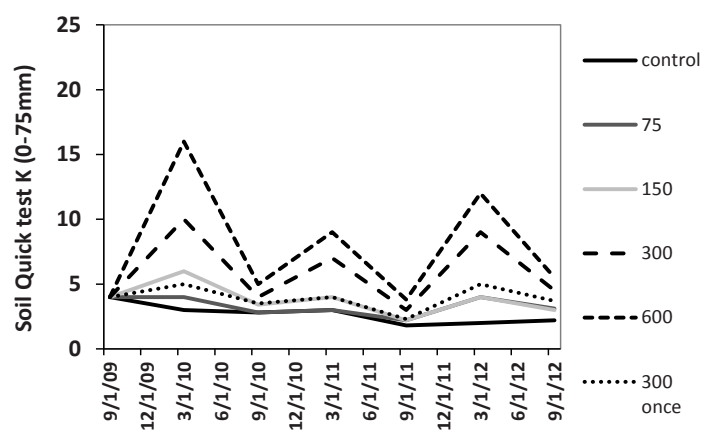

Figure 1 Effect of fertiliser potassium $(K)$ inputs $(\mathrm{kg} \mathrm{K} / \mathrm{ha} /$ $\mathrm{yr}$ ) on soil quick test (QTK, 0-75 mm) over time at Mamaku

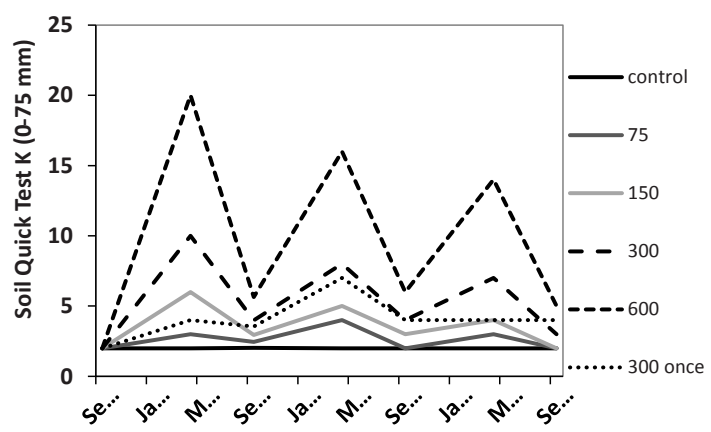

Figure 2 Effect of fertiliser potassium $(\mathrm{K})$ inputs $(\mathrm{kg} \mathrm{K} / \mathrm{ha} /$ $\mathrm{yr}$ ) on soil quick test (QTK, $0-75 \mathrm{~mm}$ ) over time at Whakamaru.

\section{Soil Test Results}

The soil QTK $(0-75 \mathrm{~mm})$ results from both trials and all treatments, from samples collected in the autumn and spring, are presented in Figures 1 and 2. There is a marked temporal effect - the autumn results $(0-75 \mathrm{~mm})$ are a) consistently higher than the spring results and b) they increase with increasing fertiliser $\mathrm{K}$ inputs. This effect was attributed to leaching of soil $\mathrm{K}$ below the 0-75 $\mathrm{mm}$ soil depth over the winter.

\section{Defining the Soil QTK Pasture Production Function}

The relationships between relative pasture production and soil QTK $(0-75 \mathrm{~mm})$, combining the data from both trials, based on either the autumn or the spring soil QTK results are shown in Figure $3 \& 4$. The relative yields are based on the average annual DM yields (over 3 years) for each treatment (excluding the unique 


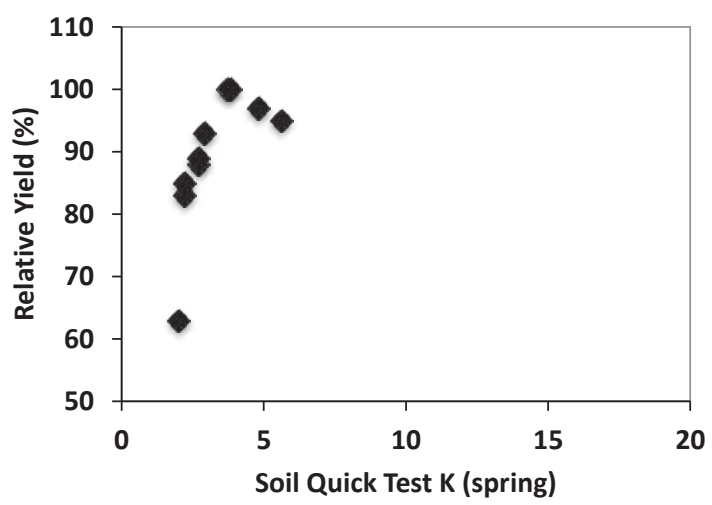

Figure 3 Relationship between soil QTK (0-75 mm) measured in spring and relative pasture production averaged over 3 years for both sites.



Figure 4 Relationship between soil QTK (0-75 mm) measured in autumn and relative pasture production averaged over 3 years for both sites.

treatment 6) for both trials, and the soil QTK results are the average treatment effects over the three years, for either the autumn or spring samples.

The response functions are clearly different depending on whether the autumn or spring soil QTK levels are used. Based on the spring soil tests it could be concluded that the biological optimal soil $\mathrm{K}$ was about 3 , as recorded by Morton et al. (2014). The response function based on the autumn soil tests suggests an optimal range of 7-10. This later conclusion is consistent with other data from pumice soils, and indeed, applies to most soil groups in New Zealand (Edmeades et al. 2010). Thus, the general conclusion of Morton et al. (2014) that these two sites are unique within the set of pumice soils, is not valid based on the autumn soil test results. More specifically, based on the autumn QTK results it is clear that a) the soil QTK required to attain $97 \%$ relative yield is about $7-10$ and that b) large rates of applied K (300-600 kg K/ha/yr) can increase the soil QTK levels to the optimal range $7-10$, contradicting the conclusions of Morton et al. (2014).
Edmeades et al. (2010) noted a consistent feature in the national set of K trials: there was a number of trials in which there was very little response to applied $\mathrm{K}$, despite the fact that the soil $\mathrm{K}$ levels were low $(<3)$. They presented evidence suggesting that this feature is unlikely to be due to large amounts of Reserve $\mathrm{K}$ (the standard explanation), but could be due to a) plant uptake of $\mathrm{K}$ from below the standard soil sampling depth $(0-75 \mathrm{~mm})$ or the length of time, following fertiliser $\mathrm{K}$ application, for the full pasture response to applied $\mathrm{K}$ to be expressed.

The large temporal effect on soil QTK levels in these trials suggests another reason why low soil QTK levels are sometimes associated with what appears to be a lack of pasture response to applied $\mathrm{K}$. The implication is that where there is significant leaching of $\mathrm{K}$ over the winter, the spring QTK levels may not represent the "true" K status of the soil throughout the previous growing season as reflected in the measured annual pasture responses to fertiliser $\mathrm{K}$, noting that fertiliser $\mathrm{K}$ was applied, in this case, in the spring and after the spring soil testing.

This problem could apply, not just to pumice soils, but to all free draining soils under high rainfall including some West Coast soils, the Sands, Podzols, Peats, and possibly the stony soils under irrigation in Canterbury.

\section{Measuring the "true" Soil K Status}

There are collateral reasons to accept that autumn soil tests are more reliable under such conditions. First it is a matter of convention that when defining pasture $x$ soil test production functions that the soil fertility status (whether for P, K or S) at the end of the year is used (Edmeades et al. 2006). Perhaps this needs to be made more explicit - the end of the year meaning the end of the growing season during which pasture production is measured. The fact that the QTK $\times$ pasture production function for these two trials based on the autumn soil test results is consistent with the general production function for all pumice soils also adds weight to this argument. Furthermore, when large rates of fertiliser K are added to soils it is expected that this will be reflected in the soil QTK levels, as it is the pasture production on $\mathrm{K}$ deficient sites.

There is a further matter to consider. Edmeades et al. (2010) suggested that QTK $(0-75 \mathrm{~mm})$ may be a proxy for the total plant available $\mathrm{K}$ in the topsoil. This possibility follows logically from the fact that a) there is for most soil groups a relationship between QTK and pasture response to applied $\mathrm{K}$ and $\mathrm{b}$ ) it is likely that, at least some soils, there are significant amounts of available $\mathrm{K}$ below $0-75 \mathrm{~mm}$, a consequence of either leaching of past surface applications of fertiliser $\mathrm{K}$ or from natural sources of available K. This hypothesis can be tested on the data from these two trials. 


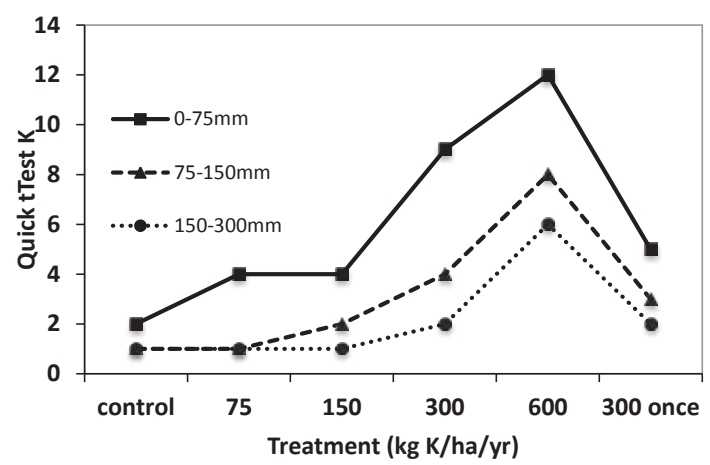

Figure 5 Effect of fertiliser $\mathrm{K}$ on soil QTK measured at the end of the trial (March 2012) at 3 depths at Mamaku.

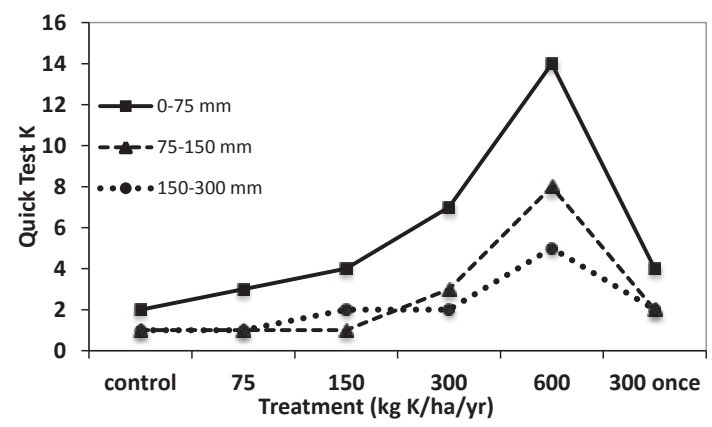

Figure 6 Effect of fertiliser $\mathrm{K}$ on soil QTK measured at the end of the trial (March 2012) at 3 depths at Whakamaru.

Figure $5 \& 6$ show the effect of applied $\mathrm{K}$ on the the soil QTK levels at three depths, at the end of the both trials. The effects of previous additions of fertiliser $\mathrm{K}$ are apparent at least at the higher $\mathrm{K}$ rates at all three soil depths, indicating soil leaching of suface applied $\mathrm{K}$. (These soil it is noted have no Reserve K.) Of particular interest, is the linear relationship between QTK $(0-75 \mathrm{~mm})$ and QTK (75-300 $\mathrm{mm})$ (Figure 7), confirming that for these soils the hypothesis is correct; under conditions of K leaching, soil QTK $(0-75 \mathrm{~mm})$ is a proxy for the amount of plant available $\mathrm{K}$ to 300 $\mathrm{mm}$. Indeed the $\mathrm{K}$ pasture production functions, either 0-75 $\mathrm{mm}$ or $0-300 \mathrm{~mm}$, are similar (data not shown). Further research is indicated.

\section{Managing Soil K Requirements}

Morton et al. (2014) effectively suggested that, because QTK (0-75 $\mathrm{mm}$ in spring) was of limiting diagnostic value, the need for $\mathrm{K}$ fertiliser or otherwise on such soils was perhaps best determined based on the $\mathrm{K}$ concentration in the clover collected in spring. They suggested that low rates of fertiliser K (75-150 kg K/ $\mathrm{ha} / \mathrm{yr}$ ) would be sufficient to increase the clover-only $\mathrm{K}$ concentration above the critical level (2.0-2.5\%). They



Figure 7 Relationship between soil QTK $(0-75 \mathrm{~mm})$ and QTK $(75-300 \mathrm{~mm})$ for both sites averaged over time (3 years).

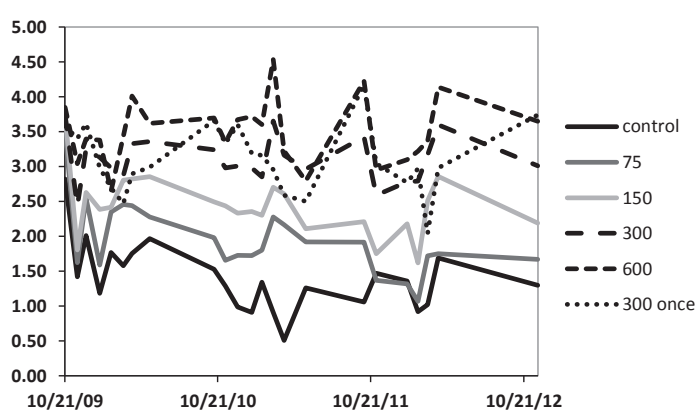

Figure 8 Effect of rate of fertiliser K on clover K concentration (\%) over time (3 years) at Mamaku.

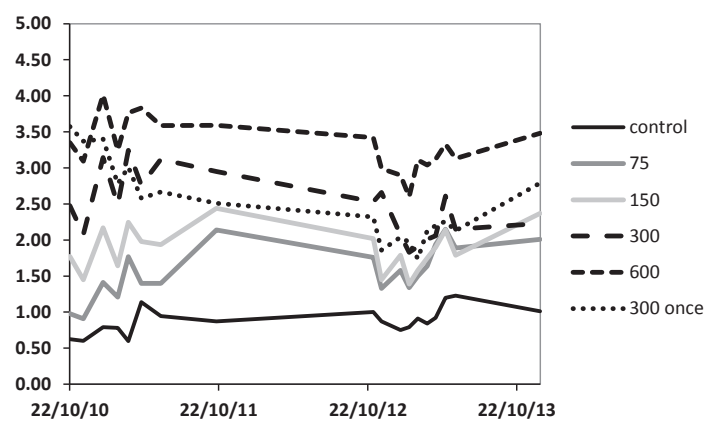

Figure 9 Effect of rate of fertiliser $\mathrm{K}$ on clover $\mathrm{K}$ concentration (\%) over time (3 years) at Whakamaru.

did not present this supporting data in their paper. It is presented in Figure $8 \& 9$ for both sites. It is clear from these data that large rates of K $(300-600 \mathrm{~kg} \mathrm{~K} / \mathrm{ha} /$ yr) were required on both sites to consistently achieve concentrations above the critical level.

The evidence summarised above suggests that on soils in which significant leaching of $\mathrm{K}$ is likely occur during winter, giving rise to large temporal effects on soil $\mathrm{K}$, that the soil QTK levels $(0-75 \mathrm{~mm})$ measured in spring must be treated with caution. Under these circumstances autumn soil test results appear to be a more reliable measure of the soil $\mathrm{K}$ status because a) 
they reflect the expected effects of increasing inputs of fertiliser K on soil QTK and on pasture growth during the growing season and b) they are consistent with the results from the national set of data on pumice soils and indeed other soil groups, in terms of defining the QTK production function. Based on the autumn soil QTK, it is apparent that soil QTK levels can be increased with suffciently high $\mathrm{K}$ inputs to the optimal range of 7-10, for near maximum pasture production. With such inputs of fertiliser $\mathrm{K}$ it is likely that the critical concentration of $\mathrm{K}$ in the clover will be achieved together with optimal clover production.

\section{Conclusions}

The conclusions reached by Morton et al. (2014) in terms of the management of soil $\mathrm{K}$ requirements of pastures on high leaching Pumice soils are valid only if reliance is placed on the spring soil QTK $(0-75 \mathrm{~mm})$, at the exclusion of the autumn QTK results. When the autumn QTK results are considered, different conclusions are possible. Importantly these conclusions are consistent with other results for pumice soils and other soils generally. It is recommended that autumn soil tests (0-75 mm), together with clover-only tests (collected in either autumn or spring ) are used as the basis for making fertiliser $\mathrm{K}$ recommendations on such soils, and that spring QTK results are treated with caution.

\section{ACKNOWLEDGEMENT}

The authors are grateful to Ballance AgriNutrients Ltd for making the raw data, but not the biometrical analysis, from these two trials available to them for the purposes of considering these results in the context of the the national set of data as published by Edmeades et al. (2010). The authors reported their results and findings to Ballance AgriNutrients Ltd in February 2013, in a report entitled: For Discussion: The diagnosis, correction and management of potassium in New Zealand pastures (February 8 2013).

\section{REFERENCES}

Edmeades, D. C.; Metherell, A.K.; Waller, J.E.; Roberts, A.H.C.; Morton, J.D. 2006. Defining the relationships between pasture production and soil $\mathrm{P}$ and the development of a dynamic P model for New Zealand pastures: a review of recent developments. New Zealand Journal of Agricultural Research 49: 207-222. Edmeades, D. C.; Morton, J.D.; Waller, J.E.; Metherell, A.K.; Roberts, A.H.C.; Carey, P. 2010. The diagnosis and correction of potassium deficiency in New Zealand pastoral soils: a review. New Zealand Journal of Agricultural Research 53: 151- 73

Morton, J.; Stafford, A.; Hawke, M. 2014. Potassium requirements of pasture on Pumice soils. Proceedings of the New Zealand Grassland Association 76: 189-192. 